Original paper

\title{
Evaluating the performance characteristics of some ion chamber dosimeters in high dose per pulse intraoperative electron beam radiation therapy
}

\author{
Hamid Reza Baghani ${ }^{\mathrm{a}}$, Mostafa Robatjazi ${ }^{\mathrm{b}, \mathrm{c}, *}$, Seied Rabi Mahdavi ${ }^{\mathrm{d}}$, \\ Seyed Rashid Hosseini Aghdam ${ }^{\mathrm{e}}$ \\ ${ }^{a}$ Physics Department, Hakim Sabzevari University, Shohada-e Hastei Blvd, P.O. 9617976487, Sabzevar, Iran \\ ${ }^{\mathrm{b}}$ Department of Medical Physics and Radiological Sciences, Sabzevar University of Medical Sciences, Shohada-e Hastei Blvd, Sabzevar University of Medical Sciences \\ Campus, P.O. 9617913112, Sabzevar, Iran \\ ${ }^{\mathrm{c}}$ Vasei Radiotherapy \& Oncology Center, Vasei Hospital, P.O. 9617913113, Sabzevar, Iran \\ ${ }^{\mathrm{d}}$ Department of Medical Physics, Iran University of Medical Sciences, Hemmat Exp. Way, Faculty of Medicine, P.O. 14496141525, Tehran, Iran \\ e Department of Radiation Medicine, Shahid Beheshti University, Daneshjoo Street, Velenjak, P.O. 1983963113, Tehran, Iran
}

\section{A R T I C L E I N F O}

\section{Keywords:}

Intraoperative electron radiotherapy

Ionometric dosimetry

Ion chamber dosimeter

Reference dosimetry

\begin{abstract}
A B S T R A C T
Introduction: Employing routine dosimetry protocols for intraoperative electron beam needs further refinements to obtain reliable results. In this regard, the performance of some cylindrical and parallel plate ion chambers for both relative and absolute dosimetry of intraoperative electron beam has been evaluated.

Materials and methods: Four different ion chambers including Semiflex and PinPoint cylindrical chambers as well as Advanced Markus and Roos parallel plate ones were employed for PDD measurement and dose rate determination in reference condition of the electron beam produced by LIAC intraoperative accelerator. The results of PDD measurements were compared with those of Gafchromic EBT2 film. Specific recommendations were followed to determine the chamber correction factors including $k_{s}$ and $k_{Q_{Q} Q_{0}}$ for absolute dosimetry in intraoperative reference condition.

Results: There was good agreement between PDDs measured by employed chambers and EBT2 film at all nominal energies. Nevertheless, Advanced Markus chamber had the best performance based on the gamma analysis results. Obtained $\mathrm{k}_{\mathrm{Q}_{\mathrm{Q}} \mathrm{Q}_{0}}$ and $\mathrm{k}_{\mathrm{s}}$ for studied ion chambers largely differed from expected values by TRS-398 protocol. The difference of measured dose rates at $12 \mathrm{MeV}$ energy by investigated chambers was less than $1.1 \%$ and Advanced Markus had the best accordance with pre-set dose rate by manufacture.

Conclusion: Results showed that ignoring the specific recommended procedures in determining the chamber correction factors causes the overestimation of the measured dose. Therefore, dedicated dosimetry protocol should be developed for high dose per pulse intraoperative electron dosimetry including all of the updated correction factors and deviations from routine ionometric electron dosimetry formalisms.
\end{abstract}

\section{Introduction}

Intraoperative electron radiotherapy (IOERT) is a treatment modality which has focused on further sparing the surrounding healthy tissues to increase the delivered dose to the target area. In IOERT, an electron beam is employed for patient irradiation. This method can be applied for treatment of different malignant tumors such as bladder, rectum, sarcoma, pancreas, breast and etc. [1-6].

Currently, some dedicated electron accelerators including Mobetron, Novac, and LIAC are introduced for IOERT. These machines are mobile and compact ones which can deliver the required radiation dose in a standard operating room [7]. These accelerators can produce the electron beam from $3 \mathrm{MeV}$ to $12 \mathrm{MeV}$ energy with high dose per pulse values up to $70 \mathrm{mGy} /$ pulse [8].

Due to the presence of high dose per pulse electron beam in IOERT, absorbed dose measurement by ion chamber dosimeters cannot be easily followed through IAEA TRS-398 [9] and AAPM TG-51 [10] protocols. Two main differences should be considered in this regard compared to the recommendations of the standard dosimetry protocols.

The first one is determining the recombination correction factor of the employed ion chamber in high dose per pulse electron beam. According to the recommendations of TRS-398 and TG-51 protocols,

\footnotetext{
* Corresponding author at: Department of Medical Physics and Radiological Sciences, Sabzevar University of Medical Sciences, Shohada-e Hastei Blvd, Sabzevar University of Medical Sciences Campus, P.O. 9617913112, Sabzevar, Iran.

E-mail addresses: H.baghani@hsu.ac.ir (H.R. Baghani), Robatjazim@medsab.ac.ir (M. Robatjazi).
} 
one can obtain $\mathrm{k}_{\mathrm{s}}$ (as defined in TRS-398) or $\mathrm{P}_{\text {ion }}$ (as defined in TG-51) through measuring the chamber response (collected charge) at two different voltages and employing the simple two voltage analysis (TVA) method. On the other hand, when the chamber is irradiated with a high dose per pulse electron beam, considerable free electron fraction is formed within the chamber active volume which is not considered by the simple TVA method [11]. Therefore, simple TVA method cannot be used for $\mathrm{k}_{\mathrm{s}}$ determination in high dose per pulse intraoperative electron beam. In such cases, one should refer to the extended Boag theory to obtain this correction factor $[11,12]$.

The second one is related to the determination of quality conversion factor $\left(\mathrm{k}_{\mathrm{Q}_{\mathrm{Q}} \mathrm{Q}_{0}}\right)$ for employed ion chambers in high dose per pulse electron beam with the quality of $Q\left(Q_{0}\right.$ is the reference beam quality for chamber calibration). In contrast to the conventional electron accelerators which are calibrated at reference depth $\left(Z_{\text {ref }}=0.6 R_{50}-0.1\right)$, dedicated IOERT accelerators are calibrated at $Z_{\text {max }}$ (depth of maximum dose) $[12,13]$. For conventional electron beam, $Z_{\text {ref }}$ and $Z_{\max }$ are close together, while the broad energy spectrum of intraoperative electron (due to both multiple electrons scattering from applicator wall as well as the presence of low electron energy component at the end of accelerator waveguide $[13,14]$ ) causes a considerable movement of the $Z_{\text {ref }}$ respect to the $Z_{\max }[8]$. The $k_{Q_{,} Q_{0}}$ factor of different ion chambers which is tabulated by standard dosimetry protocols (TRS-398 and TG-51) can only be applicable for electron calibration at $\mathrm{Z}_{\text {ref }}$. Therefore, the tabulated $\mathrm{k}_{\mathrm{Q}, \mathrm{Q}_{0}}$ values which are reported at $\mathrm{Z}_{\text {ref }}$ cannot be directly used for intraoperative electron beam calibration at $Z_{\max }$. In this case, to determine the $\mathrm{k}_{\mathrm{Q}, \mathrm{Q}_{0}}$ at $\mathrm{Z}_{\max }$, one should refer to the appendant procedure recommended by TRS-398 protocol [9].

One of the other important issues in IOERT is the lack of an imagebased treatment planning procedure [15]. Treatment planning calculations in IOERT is mainly based on the acquired percentage depth doses (PDDs) along the clinical axis of employed applicators at different energies. Therefore, the accuracy and precision in PDD measurement are of main concern which can directly affect the results of treatment planning.

As explained above, employing the ion chamber dosimeters for intraoperative electron dosimetry needs specific considerations. There are some valuable studies in this regard $[8,11,16,17]$. But, in most cases $[11,16,17]$, the main attention has been paid to the calculation of $k_{s}$ for parallel plate chambers, while other chamber correction factors such as $\mathrm{k}_{\mathrm{Q}_{\mathrm{Q}} \mathrm{Q}_{0}}$ and $\mathrm{k}_{\mathrm{pol}}$ (polarity correction factor) have not been considered in mentioned literature. Furthermore, no data has been reported for cylindrical chambers which can be used in high dose per pulse electron beam dosimetry. Besides, the accuracy of obtained PDDs for IOERT treatment planning has not been discussed in any literature.

The aim of this study is to evaluate the performance of some parallel plate and cylindrical ion chambers including Advanced Markus, Roos, PinPoint and Semiflex ones in both relative and absolute dosimetry aspects of high dose per pulse intraoperative electron beam.

\section{Materials and methods}

\subsection{Clinical accelerator}

High dose per pulse electron beam produced by LIAC12 (Sordina, SpA, Italy) accelerator was used in this study. This is a medical Linac which can produce the electron beam with the energies of $6,8,10$ and $12 \mathrm{MeV}$. The dose rate (Gy/min) of LIAC12 can change between 5 and $30 \mathrm{~Gy} / \mathrm{min}$ through adjusting the accelerator pulse repetition frequency (PRF) from 1 to $60 \mathrm{~Hz}$ [18].

Electron beam collimation is performed by means of some cylindrical PMMA applicators with the thickness and length of $5 \mathrm{~mm}$ and $60 \mathrm{~cm}$, respectively. The diameter and base angle of these applicators can vary between 3 and $10 \mathrm{~cm}$ and 0 to 45 degrees, respectively. Flat based applicator with $10 \mathrm{~cm}$ diameter is known as the reference applicator.
LIAC12 is equipped with an $820 \mu \mathrm{m}$ Aluminum scattering foil to reduce the probability of neutron production at high energies (10 and $12 \mathrm{MeV}$ ) and allow the patient irradiation in a standard and unshielded operating room [12]. The distance between the scattering foil and base of the applicator is equal to $71.3 \mathrm{~cm}$.

\subsection{Ion chambers}

Four different types of ion chambers including Advanced Markus, Roos, PinPoint and Semiflex were considered for both absolute dosimetry in the reference condition and PDD measurement. All of these chambers are manufactured by PTW Company (Freiburg, Germany).

Advanced Markus (TM34045) is a parallel plate chamber which has an air vented sensitive volume of $0.02 \mathrm{~cm}^{3}$. The chamber electrode spacing and radius of the sensitive volume are equal to $1 \mathrm{~mm}$ and $2.5 \mathrm{~mm}$, respectively. This chamber includes a $0.03 \mathrm{~mm}$ Polyethylene entrance foil and $0.87 \mathrm{~mm}$ PMMA waterproof cap which are equivalent to $1.06 \mathrm{~mm}$ thickness of water. The chamber reference point is located at the center of the entrance foil inner surface. The chamber is calibrated in the reference quality of ${ }^{60} \mathrm{Co}\left(\mathrm{Q}_{0}\right)$ in terms of absorbed dose to water $\left(\mathrm{N}_{\mathrm{D}, \mathrm{w}, 60 \mathrm{Co}}(\mathrm{Gy} / \mathrm{C})\right)$ and its recommended operating voltage is $300 \mathrm{~V}$ [19].

Roos (TM34001) is also an air vented parallel plate chamber with a sensitive volume of $0.35 \mathrm{~cm}^{3}$. Chamber electrode spacing and radius of the sensitive volume are $2 \mathrm{~mm}$ and $7.8 \mathrm{~mm}$, respectively. In contrast to Advanced Markus chamber, Roos is a waterproof dosimeter which doesn't need to any protection cap. Entrance window of Roos chamber includes $1.01 \mathrm{~mm}$ PMMA, $0.02 \mathrm{~mm}$ graphite and $0.1 \mathrm{~mm}$ varnish which totally are equivalent to $1.3 \mathrm{~mm}$ thickness of water. The chamber calibration factor is also obtained in the reference quality of ${ }^{60} \mathrm{Co}$ $\left(\mathrm{N}_{\mathrm{D}, \mathrm{w}, 60 \mathrm{Co}}(\mathrm{Gy} / \mathrm{C})\right)$. The chamber reference point is located at the chamber center and $1.12 \mathrm{~mm}$ below its surface. The recommended chamber voltage is equal to $200 \mathrm{~V}$ [19].

PinPoint (TM31014) is a cylindrical waterproof chamber with a small air vented sensitive volume of $0.015 \mathrm{~cm}^{3}$. The chamber sensitive volume dimensions are equal to $1 \mathrm{~mm}$ (radius) $\times 5 \mathrm{~mm}$ (length). The Pinpoint chamber has an equivalent electrode spacing of $0.963 \mathrm{~mm}$ which is calculated through the following Equation [20]:

$d_{c y l}=(a-b)\left[\frac{a+b}{a-b} \frac{\ln \left(\frac{a}{b}\right)}{2}\right]^{\frac{1}{2}}$

where $d_{\text {cyl }}$ is the equivalent electrode spacing, a is the inner radius of the external chamber electrode and $b$ is the outer radius of the internal chamber electrode. The values of $a$ and $b$ for PinPoint chamber are equal to $1 \mathrm{~mm}$ and $0.15 \mathrm{~mm}$, respectively. The chamber reference point is located on the chamber axis and $3.4 \mathrm{~mm}$ distance from the chamber tip. Chamber is calibrated in ${ }^{60} \mathrm{Co}$ reference beam quality $\left(\mathrm{N}_{\mathrm{D}, \mathrm{w}, 60 \mathrm{Co}}(\mathrm{Gy})\right.$ C)) and its recommended operating voltage is equal to $400 \mathrm{~V}$ [19].

Semiflex (TM31010) is also an air vented cylindrical waterproof chamber with the nominal sensitive volume of $0.125 \mathrm{~cm}^{3}$. The radius and length of its sensitive volume are equal to $2.75 \mathrm{~mm}$ and $6.5 \mathrm{~mm}$, respectively. According to the Eq. (1) and considering a $=2.75 \mathrm{~mm}$ and $\mathrm{b}=0.55 \mathrm{~mm}$, the equivalent chamber electrode spacing will be obtained as $2.42 \mathrm{~mm}$. The reference point of the chamber is located on chamber axis and $4.5 \mathrm{~mm}$ distance from the chamber tip. This chamber is calibrated in terms of absorbed dose to water at ${ }^{60} \mathrm{Co}$ reference beam quality $\left(\mathrm{N}_{\mathrm{D}, \mathrm{w}, 60 \mathrm{Co}}(\mathrm{Gy} / \mathrm{C})\right)$ and its recommended voltage is equal to $400 \mathrm{~V}$ [19].

The calibration factors of employed ion chambers $\left(\mathrm{N}_{\mathrm{D}, \mathrm{w}, 60 \mathrm{C}_{0}}\right)$ are presented in Table 1 . It should be mentioned that the reported calibration factors are corrected for the polarity effect. 
Table 1

The operating voltage and reference calibration factor, $\mathrm{N}_{\mathrm{D}, \mathrm{W}, \mathrm{Qo}}\left(\mathrm{Q}_{0}={ }^{60} \mathrm{Co}\right)$, of employed ion chambers.

\begin{tabular}{llll}
\hline $\begin{array}{l}\text { Chamber trade } \\
\text { name }\end{array}$ & $\begin{array}{l}\text { Chamber type } \\
\text { number }\end{array}$ & $\begin{array}{l}\text { Operating voltage } \\
\text { (V) }\end{array}$ & $\begin{array}{l}\text { Calibration Factor } \\
\mathrm{N}_{\mathrm{D}, \mathrm{W}, \mathrm{Q} 0}(\mathrm{~Gy} / \mathrm{C})\end{array}$ \\
\hline $\begin{array}{l}\text { Advanced Markus } \\
\text { Pinpoint }\end{array}$ & 34045 & 300 & $1.471 \times 10^{9}$ \\
Semiflex & 31014 & 400 & $2.438 \times 10^{9}$ \\
Roos & 31010 & 400 & $3.104 \times 10^{8}$ \\
& 34001 & 200 & $8.313 \times 10^{7}$ \\
\hline
\end{tabular}

\subsection{PDD measurements}

To measure the PDDs at different energies of 6, 8, 10 and $12 \mathrm{MeV}$, a remote automatic field scanning procedure was performed inside an MP3-XS water phantom (PTW, Germany) by means of a TANDEM digital electrometer and a TBA control unit (PTW, Germany). All of the measurements were accomplished along the clinical axis of the reference applicator (flat based one with $10 \mathrm{~cm}$ diameter). To this end, the applicator edge was held on the water surface $(\mathrm{SSD}=71.3 \mathrm{~cm})$ and emerging electrons from the reference applicator were scanned with $2 \mathrm{~mm}$ increments using different chambers. Finally, the obtained depth ionization curves were converted to the PDD curves through applying the tabulated water to air stopping power ratios (reported by TRS-398 protocol) to the corresponding chamber response at different depths. Although the water to air stopping power ratios for intraoperative electron beam differs from those tabulated by TRS-398 protocol for conventional electron beam, this discrepancy adds a negligible uncertainty to the obtained results [21].

It should be mentioned that the Roos chamber was not used for PDD measurement, because of the large $\mathrm{k}_{\mathrm{s}}$ values of this chamber at different measurement depths.

Due to the relatively large sensitive volume of Semiflex chamber, the response of this chamber at different depths was corrected for recombination effect, while this procedure was ignored for Advanced Markus and PinPoint chambers because of their small sensitive volume [22]. In all of the measurements, a second Semiflex chamber (TM31010) was employed as the reference dosimeter to monitor the variations of accelerator output during the field scanning and PDD measurement [23].

\subsection{Film dosimetry}

As recommended by Robatjazi et al. [24], Gafchromic EBT2 film (International specialty products, ISP) was employed to measure the PDDs of the intraoperative electron beam at different energies.

Due to the both energy and dose rate independent response of EBT2 film [15], employed films were calibrated by $9 \mathrm{MeV}$ electron beam of a Varian 2100C/D external radiotherapy accelerator and its dose-response curve was extracted at the red channel [24].

To measure the film based PDDs, $12 \times 10 \mathrm{~cm}^{2}$ pieces of EBT2 film were attached to the end of reference applicator and the applicator was placed inside the water phantom in such a way that its edge was in touch with the water phantom surface (as shown in Fig. 1).

This procedure was followed for all electron energies and obtained film responses were converted to the dose through the obtained calibration curve. The Microtek 9800XL scanner was used for film scanning in transmission mode and red channel film response was used at all of the performed analysis.

Finally, the ionometric measured PDDs at different energies were quantitatively compared with those obtained by Gafchromic EBT2 film through global gamma analysis [25] to evaluate how close are the obtained data with different dosimeters. To have an accurate evaluation, the dose difference (DD) and distance to agreement (DTA) in gamma index calculations were set to $1 \%$ and $1 \mathrm{~mm}$, respectively. Lower gamma index values indicate the better accordance between the results. It should be mentioned that the film measured PDDs were considered as the reference ones in gamma index calculations. The DoseLab Pro software was used for gamma analysis.

\subsection{Absolute dosimetry in reference condition}

In order to determine the absorbed dose to water (in terms of cGy/ MU), the general dosimetry formalism recommended by TRS-398 protocol was followed [9]. According to this dosimetry formalism, one can determine the absorbed dose to water through Eq. (2):

$D_{w, Q}=M_{Q, c o r} N_{D, w, Q_{0}} k_{Q, Q_{0}}$

$M_{Q, \text { cor }}=M_{\text {raw }} k_{\text {pol }} k_{s} k_{T, P} k_{\text {elec }}$

where $\mathrm{D}_{\mathrm{w}}, \mathrm{Q}$ is the absorbed dose to water at the beam quality of $\mathrm{Q}$, $\mathrm{N}_{\mathrm{D}, \mathrm{w},},{ }^{60} \mathrm{Co}$ is the chamber calibration factor at reference beam quality of $\mathrm{Q}_{0}\left({ }^{60} \mathrm{Co}\right), \mathrm{k}_{\mathrm{Q}, \mathrm{Q}_{0}}$ is the quality conversion factor which considers the difference between employed beam quality $(\mathrm{Q})$ and reference beam quality $\left(\mathrm{Q}_{0}\right), \mathrm{M}_{\mathrm{Q}}$, cor is the corrected chamber response at beam quality of $\mathrm{Q}, \mathrm{M}_{\text {raw }}$ is the uncorrected chamber response, $\mathrm{k}_{\mathrm{pol}}$ is the polarity correction factor, $\mathrm{k}_{\mathrm{s}}$ is the recombination correction factor, $\mathrm{k}_{\mathrm{T}, \mathrm{p}}$ is the temperature and pressure correction factor and $\mathrm{k}_{\mathrm{elec}}$ is the electrometer calibration factor.

The calculation methods for these correction factors are completely explained by TRS-398 protocol. But, as mentioned earlier, the recommended methods for $\mathrm{k}_{\mathrm{Q}, \mathrm{Q}_{0}}$ and $\mathrm{k}_{\mathrm{s}}$ determination are not applicable in high dose per pulse electron beam. Therefore, all of the abovementioned correction factors except $\mathrm{k}_{\mathrm{s}}$ and $\mathrm{k}_{\mathrm{Q}, \mathrm{Q}_{0}}$, were determined according to the TRS-398 recommendations.

The electrometer calibration factor $\left(\mathrm{k}_{\text {elec }}\right)$ was considered as 1 . In addition, all of the measurements were performed at $19.7^{\circ} \mathrm{C}$ temperature and pressure of 850 mbar, so that the $\mathrm{k}_{\mathrm{T}, \mathrm{p}}$ factor was obtained as 1.191. Due to the fact that the reported chamber calibration factors were corrected for the polarity effect, the $\mathrm{k}_{\mathrm{pol}}$ was determined by chamber reading at both positive and negative polarities $\left(\mathrm{M}_{+}, \mathrm{M}_{-}\right)$and employing the Eq. (3).

$k_{p o l}=\frac{\left|M_{+}\right|+\left|M_{-}\right|}{2 M_{+}}$

If the chamber calibration factor $\left(N_{D, w, Q_{0}}\right)$ has not been corrected for polarity effect, the Eq. (3) cannot be applied for absolute dose measurement and is only suitable for relative dosimetry purposes. In this condition, the Eq. (3) should be substituted by the following equation for absolute dose measurement [9]:

$k_{p o l}=\frac{\left(k_{p o l}\right)_{Q}}{\left(k_{p o l}\right)_{Q_{0}}}$

where $\left(k_{p o l}\right)_{Q}$ and $\left(k_{p o l}\right)_{Q_{0}}$ are the polarity correction factor at the beam quality of $\mathrm{Q}$ (user beam quality) and $\mathrm{Q}_{0}$ (reference beam quality), respectively. Nevertheless, the obtained data by Eq. (3) can be still considered as a measure of the polarity effect strength for ion chamber dosimeters in this situation.

All of the irradiations were performed at the reference condition including $10 \mathrm{~cm}$ reference applicator, $71.3 \mathrm{~cm} \mathrm{SSD}$ and measurement depth of $Z_{\max }$. It should be mentioned that the effective point of cylindrical chambers (PinPoint and Semiflex chambers) were positioned at $0.5 r_{\text {cav }}$ deeper than $Z_{\max }$ to compensate the gradient effect [9].

\subsubsection{Quality conversion factor}

The presented $\mathrm{k}_{\mathrm{Q}_{\mathrm{Q}} \mathrm{Q}_{0}}$ values for conventional electron beam dosimetry can only be used at $\mathrm{Z}_{\text {ref }}$. But as mentioned earlier, the intraoperative electron beam should be calibrated at $Z_{\text {max }}$. Due to the different water to air stopping power ratios in these two calibration depths, the quality conversion factors at $Z_{\text {ref }}$ and $Z_{\max }$ are different. Furthermore, this discrepancy is more severe for intraoperative electron beam because $Z_{\text {ref }}$ and $Z_{\text {max }}$ differ up to $77 \%$ [8]. As a consequence, one 


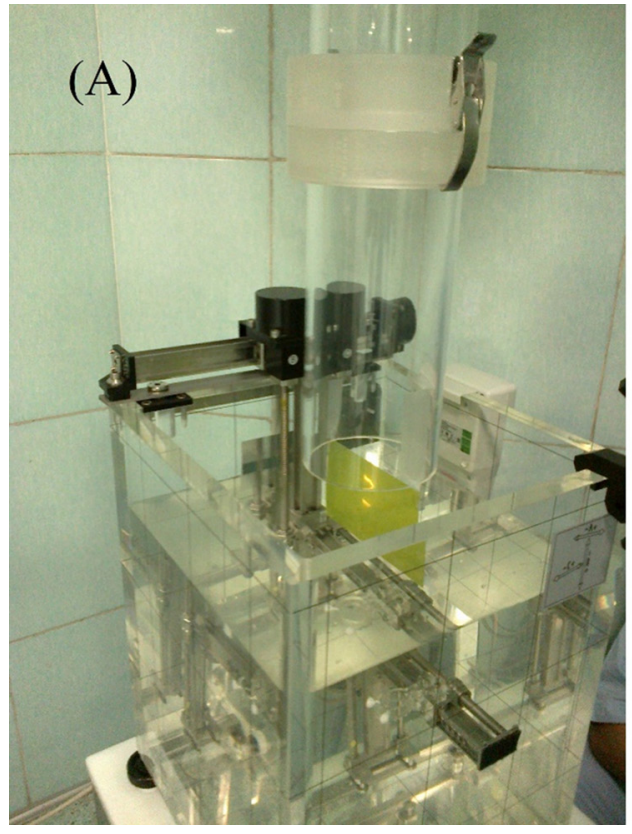

Fig. 1. Practical setup for EBT2 film-based PDD measurements at different energies. surface of water phantom.

cannot directly use the TRS-398 reported $\mathrm{k}_{\mathrm{Q}_{\mathrm{Q}} \mathrm{Q}_{0}}$ values for absolute dosimetry at $\mathrm{Z}_{\text {max }}$. Instead, the $\mathrm{k}_{\mathrm{Q}_{\text {, }} \mathrm{Q}_{0}}$ at $\mathrm{Z}_{\max }$ should be separately determined by the following Equation [8]:

$k_{Q, Q_{0}, Z_{\max }}=k_{Q, Q_{0}, Z_{\text {ref }}}\left(\frac{S_{\text {air }}^{w}\left(Z_{\max }\right)}{S_{\text {air }}^{w}\left(Z_{\text {ref }}\right)}\right)$

where $\mathrm{k}_{\mathrm{Q}_{0}, \mathrm{Q}_{0}, \mathrm{Z}_{\text {ref }}}$ is the quality conversion factor at $\mathrm{Z}_{\mathrm{ref}}, \mathrm{S}_{\mathrm{air}}^{\mathrm{w}}\left(\mathrm{Z}_{\max }\right)$ and $S_{\text {air }}^{\mathrm{W}}\left(\mathrm{Z}_{\text {ref }}\right)$ are the water to air stopping power ratio at $\mathrm{Z}_{\text {max }}$ and $\mathrm{Z}_{\text {ref }}$, respectively.

The recommended $\mathrm{k}_{\mathrm{Q}_{\mathrm{Q}} \mathrm{Q}_{0}}$ values at $\mathrm{Z}_{\mathrm{ref}}$ as a function of beam quality index $\left(R_{50}\right)$, are reported in literature for studied chambers $[9,19]$.

The $\mathrm{k}_{\mathrm{Q}, \mathrm{Q}_{0}}$ values for Advanced Markus chamber were taken from the reported ones by manufacture (PTW), which were calculated according to the TRS-398 protocol [19]. Due to the employment of cylindrical chambers at beam quality indexes higher than $4 \mathrm{~g} / \mathrm{cm}^{2}$ [9], the $\mathrm{k}_{\mathrm{Q}_{\text {, }}}$ values for Semifelx and PinPoint chambers were only obtained at $12 \mathrm{MeV}$ electron energy $\left(\mathrm{R}_{50}\right.$ higher than $\left.4 \mathrm{~g} / \mathrm{cm}^{2}\right)$. But, the values of $\mathrm{k}_{\mathrm{Q}, \mathrm{Q}_{0}}$ for parallel plate ion chambers (Roos and Advanced Markus) were calculated at all electron energies.

The value of $S_{\text {air }}^{\mathrm{w}}$ at $Z_{\text {ref }}$ and each other arbitrary depth (Z) can also be calculated by Eqs. (6) and (7), respectively [9].

$S_{\text {air }}^{w}\left(Z_{\text {ref }}\right)=1.253-0.1487\left(R_{50}\right)^{0.214}$

$S_{\text {air }}^{w}(Z)=\frac{a+b x+c x^{2}+d y}{1+e x+f x^{2}+g x^{3}+h y}$

where $\mathrm{R}_{50}$ is the electron beam quality index in terms of $\mathrm{cm}$ in water, $x=\ln \left(R_{50}\right)$ and $\mathrm{y}=\mathrm{Z} / \mathrm{R}_{50}$. The constant coefficients of $\mathrm{a}, \mathrm{b}, \mathrm{c}, \mathrm{d}, \mathrm{e}, \mathrm{f}, \mathrm{g}$, and $\mathrm{h}$ have been also reported in Table 2 [9].

Now, the values of $\mathrm{k}_{\mathrm{Q}, \mathrm{Q}_{0}, \mathrm{Z}_{\max }}$ at different intraoperative electron energies can be calculated using Eq. (6), Eq. (7) and reported $\mathrm{k}_{\mathrm{Q}_{\mathrm{Q}}, \mathrm{Z}_{\mathrm{ref}}}$ values.

\subsubsection{Recombination correction factor}

As previously mentioned, the simple TVA method cannot be used to determine the $\mathrm{k}_{\mathrm{s}}$ of employed ion chambers in high dose per pulse electron beam. Instead, the extended Boag theory and recommended formalisms by Laitano or Di Martino should be employed [11,26]. The recommended formalism by Laitano was used to determine the $\mathrm{k}_{\mathrm{s}}$ of

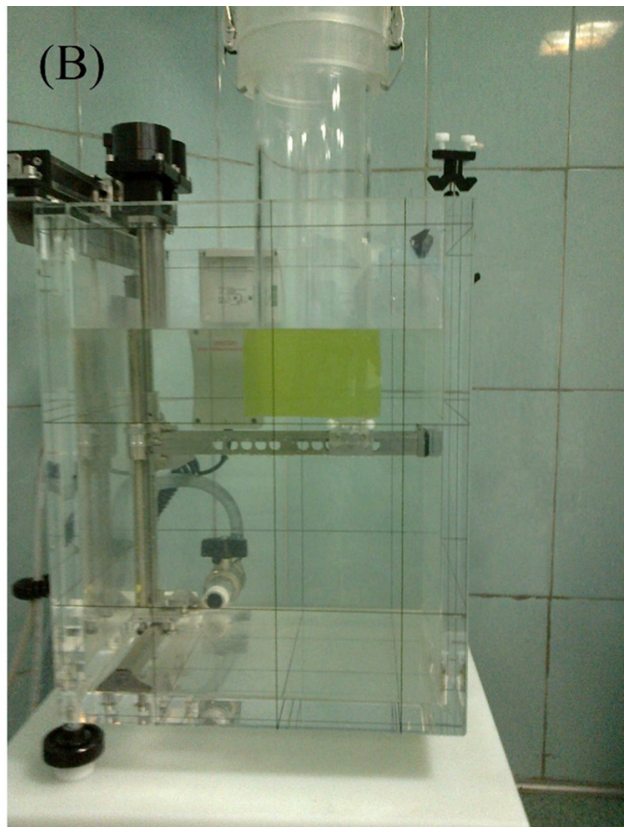

(A) The attached film to applicator edge, (B) adjusting the applicator edge to the Table 2

Numerical values of constant coefficients which are presented in Eq. (5).

\begin{tabular}{ll}
\hline Parameter & Value \\
\hline a & 1.075 \\
b & -0.5087 \\
c & 0.0887 \\
d & -0.084 \\
e & -0.4281 \\
f & 0.0646 \\
g & 0.00309 \\
h & -0.125 \\
\hline
\end{tabular}

employed chambers in different intraoperative electron beam energies.

As described by Boag theory [27], there are three general models for $\mathrm{k}_{\mathrm{s}}$ calculation of ion chambers including:

$\frac{1}{k_{s}}=\frac{1}{u} \ln \left(1+\frac{e^{p u}-1}{p}\right) \quad$ First Boag Model

$\frac{1}{k_{s}}=p+\frac{1}{u} \ln [1+(1-p) u] \quad$ Second Boag Model

$$
\begin{aligned}
\frac{1}{k_{s}}= & -\sqrt{1-p} \\
& +\frac{1}{u} \ln \left[1+\frac{e^{(1-\sqrt{1-p})(\sqrt{1-p}) u}-1}{1-\sqrt{1-p}}\right] \quad \text { Third Boag Model }
\end{aligned}
$$

where $\mathrm{p}$ is the produced free electron fraction inside the chamber sensitive volume and $\mathrm{u}$ is a quantity which depends on the chamber electrode spacing, chamber voltage and charge density $\left(\mathrm{C} / \mathrm{m}^{3}\right)$ per pulse inside the chamber sensitive volume.

As shown by above Equations (Eqs. (8)-(10)), the $k_{s}$ value depends on the both $\mathrm{p}$ and $\mathrm{u}$ parameters. Calculation of these two parameters is fully explained by Laitano et al. [11].

p parameter can be obtained by inserting the chamber electrode spacing (equivalent electrode spacing for cylindrical chambers) and chamber voltage into the presented formula by Laitano et al [11].

In order to calculate the $u$ parameter for employed ion chambers at the operating voltage of $\mathrm{V}_{1}$ (employed voltage for electron dosimetry), 
each chamber was irradiated in reference condition. Then, its response in terms of collected charge of $\mathrm{Q}_{1}$ and $\mathrm{Q}_{2}$ was respectively obtained at two different applied voltages of $V_{1}$ and $V_{2}\left(V_{1}\right.$ was higher than $\left.V_{2}\right)$. Afterward, the values of the $u$ parameter at different electron energies were obtained through solving Eqs. (11)-(13) (according to each corresponding Boag model).

$$
\frac{V_{1} \ln \left(1+\frac{e^{p_{1} u}-1}{p_{1}}\right)}{V_{2} \ln \left(1+\frac{e^{\frac{V_{1} p_{2} u}{V_{2}}}-1}{p_{2}}\right)}-\frac{Q_{1}}{Q_{2}}=0
$$

$\frac{p_{1} u+\ln \left(1+\left(1-p_{1}\right) u\right)}{p_{2} u+\frac{V_{2} \ln \left(1+\frac{\left(1-p_{2}\right) u V_{1}}{V_{2}}\right)}{V 1}}-\frac{Q_{1}}{Q_{2}}=0$

$$
\begin{aligned}
& \frac{\left(1-\sqrt{1-p_{1}}\right) u_{1}+\ln \left[1+\frac{1}{1-\sqrt{1-p_{1}}}\left(e^{\left(1-\sqrt{1-p_{1}}\right)\left(\sqrt{1-p_{1}}\right) u_{1}}-1\right)\right]}{\left(1-\sqrt{1-p_{2}}\right) u_{1}+\frac{V_{2}}{V_{1}} \ln \left[1+\frac{1}{1-\sqrt{1-p_{2}}}\left(e^{\left(1-\sqrt{1-p_{2}}\right)\left(\sqrt{1-p_{2}}\right)\left(\frac{V_{1}}{V_{2}}\right) u_{1}}-1\right)\right]} \\
& -\frac{Q_{1}}{Q_{2}}=0
\end{aligned}
$$

It should be mentioned that the above Equations were solved using an in-house written bisection numerical program developed by Maple 16.02 software (Maplesoft, Waterloo Maple Inc).

Finally, having the $\mathrm{u}$ and $\mathrm{p}$ parameters, the values of $\mathrm{k}_{\mathrm{s}}$ for different Boag models were calculated by Eqs. (8)-(10).

\section{Results and discussion}

\subsection{Measured PDDs}

The measured PDDs at different intraoperative electron energies of $6,8,10$ and $12 \mathrm{MeV}$ acquired by different ion chambers as well as Gafchromic EBT2 film, are shown in Figs. 2-5, respectively. The results of gamma analysis for PDD comparison at different energies are also presented at corresponding Figures.

As shown in Fig. 2, the acquired PDD with Advanced Markus chamber at $6 \mathrm{MeV}$ energy has the better accordance with the film measured PDD (mean gamma index of 0.55) compared to that of Semiflex and PinPoint chambers (mean gamma index of 0.62 and 1.11, respectively).

As indicated by Fig. 3, Semiflex measured PDD at $8 \mathrm{MeV}$ energy has the best agreement with the film dosimetry results (mean gamma index of 0.76) while PDDs related to Advanced Markus and PinPoint

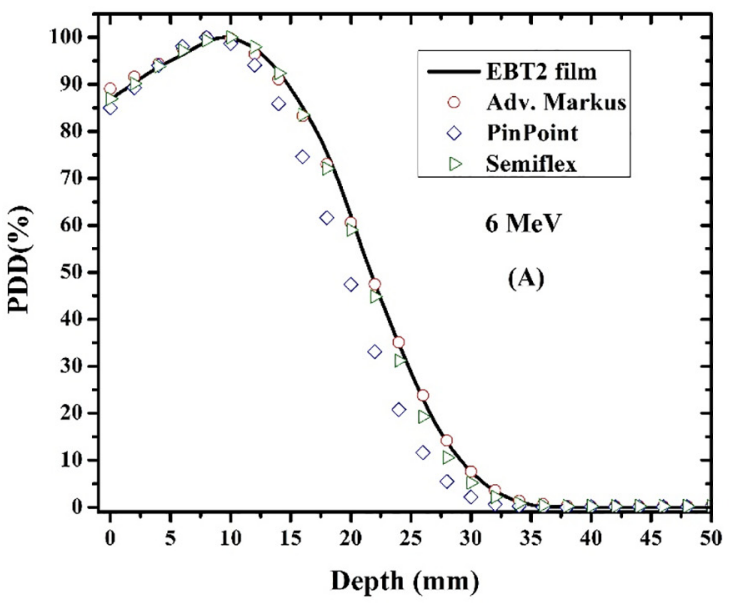

chambers had a slightly higher mean gamma index $(0.78$ and 0.84 , respectively) and therefore a lower accordance with the film measured PDD.

Comparison of the obtained PDDs at $10 \mathrm{MeV}$ energy in Fig. 4 showed that the results of Advanced Markus chamber have the best agreement with film dosimetry ones (mean gamma index of 0.3 ) while PinPoint and Semiflex results have a degraded agreement (mean gamma index of 0.78 and 1.11 , respectively).

Presented results by Fig. 5 demonstrate that the measured PDD by Advanced Markus chamber at $12 \mathrm{MeV}$ energy has the best accordance with that of film dosimetry (mean gamma index of 0.88), while the Semiflex and PinPoint chambers had a lower agreement with the reference film dosimetry results (mean gamma index of 1.05 and 1.27, respectively).

Generally, the obtained PDDs by each ion chamber at different energies had good accordance with those measured by Gafchromic EBT2 film. Nevertheless, comparison of the obtained results showed that the Advanced Markus chamber has the best performance in percentage depth dose measurement of LIAC intraoperative electron beam due to the lowest mean gamma index value. On the other hand, PinPoint chamber would be more accurate in measuring the surface dose which is of main concern in intraoperative radiotherapy because of involvement as a target part.

The extracted PDD parameters including $\mathrm{D}_{\mathrm{s}}$ (surface dose in terms of maximum percentage dose), $\mathrm{R}_{100}$ (depth of maximum dose), $\mathrm{R}_{90}$ (Depth $90 \%$ dose), $R_{50}$ (depth of $50 \%$ dose or electron beam quality index) and $R_{p}$ (practical range) at different electron energies are reported in Table 3.

\subsection{Polarity correction factor}

The values of $k_{\text {pol }}$ for chambers understudy at different electron energies are reported in Table 4. It should be mentioned that the values of $\mathrm{k}_{\mathrm{pol}}$ were measured at the reference condition.

As presented by Table 4, PinPoint and Semiflex chambers show the greatest polarity effect which can reach up to $3 \%$. On the other hand, the Advanced Markus and Roos chambers show the lowest polarity effect at different electron energies. This difference can be mainly due to the various design and configuration (geometry) of parallel plate chambers (Roos and Advanced Markus chambers) respect to the cylindrical ones (PinPoint and Semiflex chambers).

\subsection{Quality conversion factor}

The values of quality conversion factors $\left(\mathrm{k}_{\mathrm{Q}_{\mathrm{Q}}}\right)$ at different electron

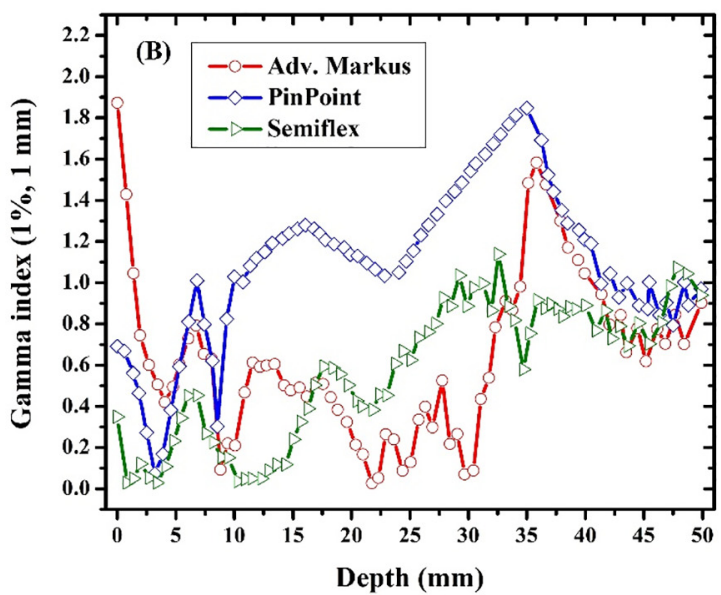

Fig. 2. Comparison of measured PDDs by different ion chambers and EBT2 film dosimetry at $6 \mathrm{MeV}$ electron energy. Corresponding gamma analysis for each ion chamber is also presented. 

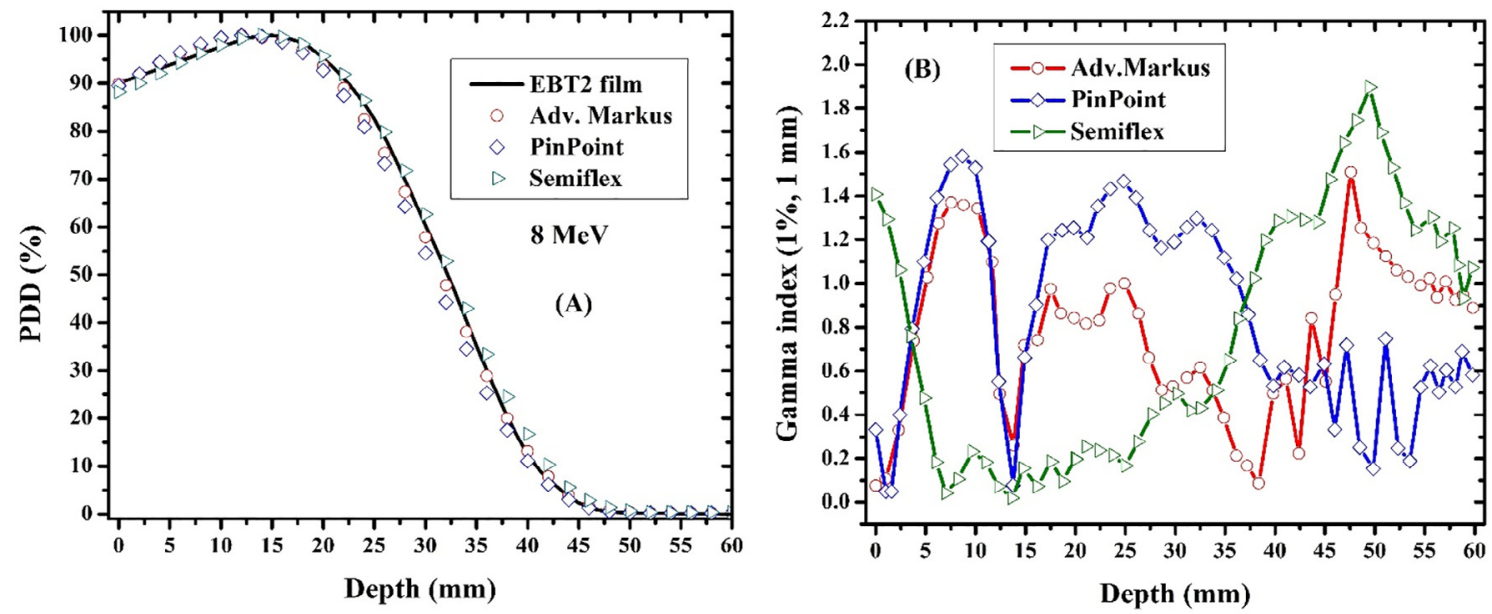

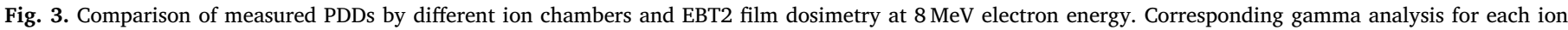
chamber is also presented.

energies of LIAC accelerator are listed in Table 5. Due to the lack of $\mathrm{k}_{\mathrm{Q}, \mathrm{Q}_{0}}$ factors at the beam quality indexes lower than $4 \mathrm{~g} / \mathrm{cm}^{2}, \mathrm{k}_{\mathrm{Q}, \mathrm{Q}_{0}}$ for cylindrical chambers are only reported at $12 \mathrm{MeV}$ electron energy.

As reported by Table 5 , the obtained $\mathrm{k}_{\mathrm{Q}_{\mathrm{Q}} \mathrm{Q}_{0}}$ values at $\mathrm{Z}_{\max }$ are different from those obtained at $Z_{\text {ref. }}$. Due to the considerable difference between $Z_{\text {ref }}$ and $Z_{\text {max }}$ of intraoperative electron beam [8], the stopping power ratio $\left(S_{\text {air }}^{w}\right)$ considerably changes from $Z_{\text {ref }}$ to $Z_{\text {max }}$. Therefore, thek $\mathrm{Q}_{\mathrm{Q}, \mathrm{Q}_{0}}$ value at $\mathrm{Z}_{\max }$ would be different from that of $\mathrm{Z}_{\text {ref }}$, based on Eq. (5). It was also supposed that the chamber perturbation correction factors including displacement correction for cylindrical chambers $\left(\mathrm{P}_{\text {dis }}\right)$, cavity correction $\left(\mathrm{P}_{\text {cav }}\right)$, chamber wall correction, $\left(\mathrm{P}_{\text {wall }}\right)$, and central electrode correction, $\left(\mathrm{P}_{\text {cel }}\right)$, would not change with the variations of depth or electron energy. Therefore, as recommended by TRS398 protocol, the total uncertainties higher than $1.2 \%$ and $1.7 \%$ are associated with the calculated $\mathrm{k}_{\mathrm{Q}_{\mathrm{Q}_{0}}}$ for cylindrical and parallel plate chambers, respectively.

\subsection{Recombination correction factor}

The obtained ion recombination correction factors $\left(\mathrm{k}_{\mathrm{s}}\right)$ for investigated ion chambers, according to the three different Boag models, are presented in Fig. 6.

As illustrated by Fig. 6 , the $k_{s}$ values at different energies are lower than those obtained by simple TVA method.

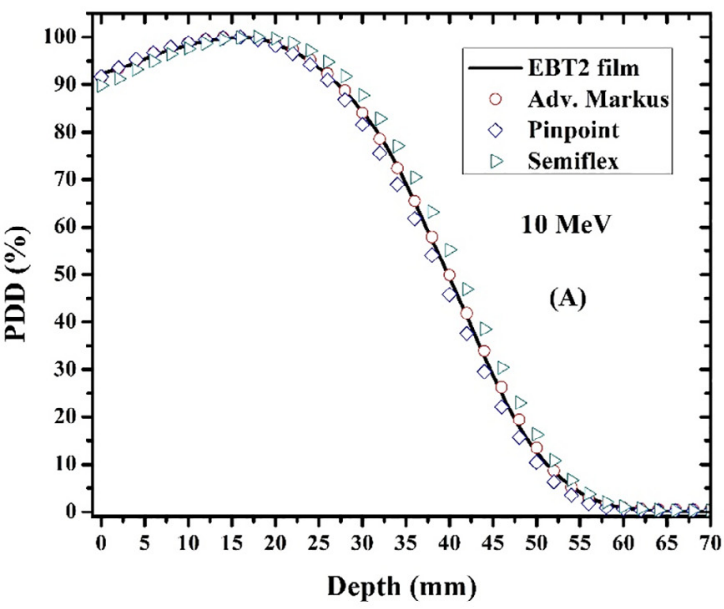

Due to the high dose per pulse nature of electron beam from dedicated IOERT accelerators, a considerable free electron fraction is formed within the chamber sensitive volume. on the other hand, The simple TVA method ignores the free electron fraction during the charge collection efficiency determination. This fact finally leads to the overestimation of the recombination correction factor by this method. Therefore, simple TVA method is only valid and reliable in conditions that the collected free electron fraction is negligible.

For all studied chambers, the difference between obtained $\mathrm{k}_{\mathrm{s}}$ values by two methods (simple TVA method and extended Boag models), increases with electron energy increment. With increasing the incident electron energy, the velocity of produced electrons inside the chamber sensitive volume increments too [28]. As a consequence, more electrons can escape from attachment and collected free electrons would be increased. Therefore, the absolute difference between calculated $k_{s}$ values would be increased.

The relative difference between the obtained $k_{s}$ by three different Boag models was not remarkable (less than $0.5 \%$ ). As mentioned by Laitano et al., with the increasing the applied voltage to ion chamber dosimeters, the consistency of obtained $\mathrm{k}_{\mathrm{s}}$ by three Boag models increases [11]. Nevertheless, as recommended by the same authors, the third Boag model would be the most accurate one in determining the $\mathrm{k}_{\mathrm{s}}$ of employed ion chambers in high dose per pulse electron beam [11].

Comparison of the obtained $\mathrm{k}_{\mathrm{s}}$ for studied chambers showed that the

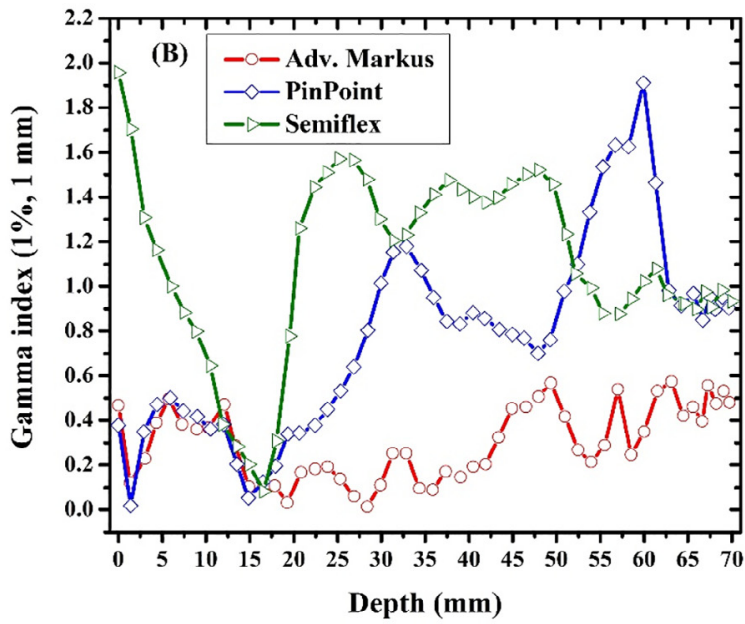

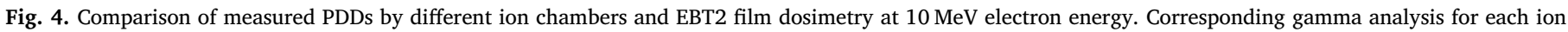
chamber is also presented. 

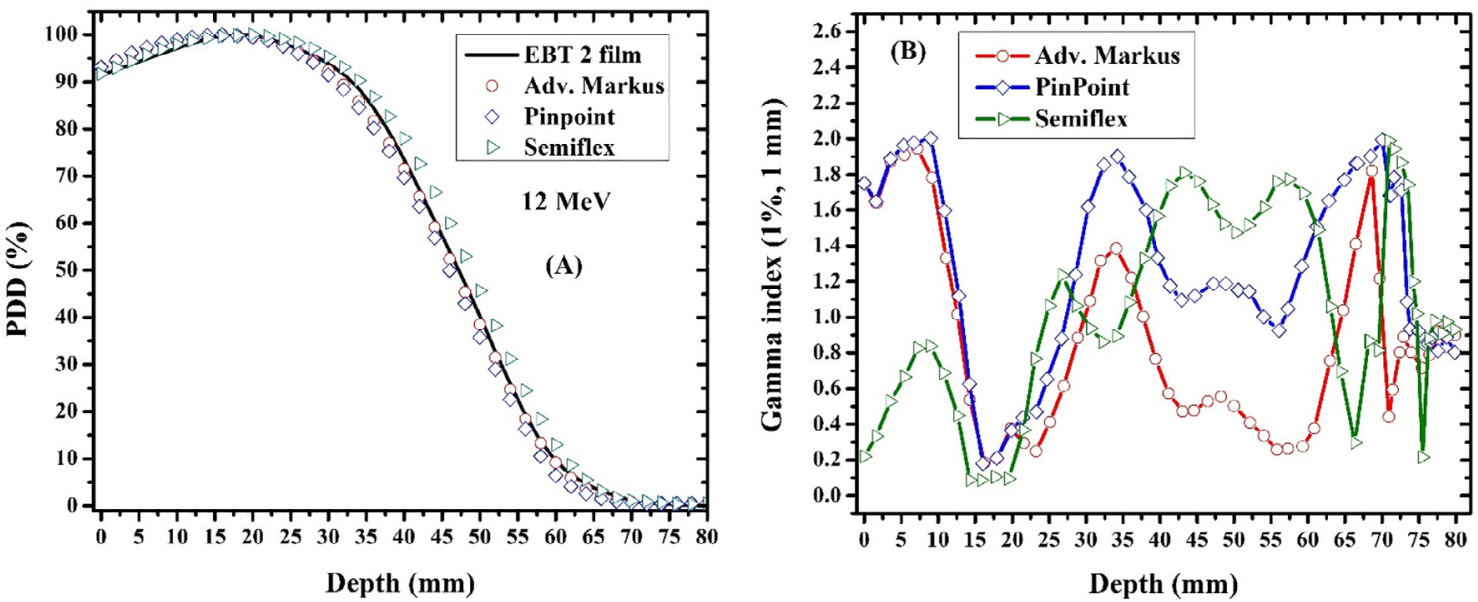

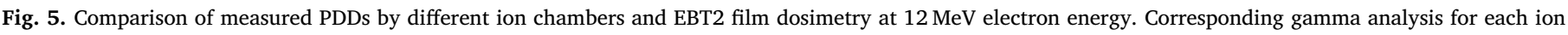
chamber is also presented.

Table 3

Dosimetric parameters of acquired PDDs with different ion chambers at different energies of intraoperative electron beam.

\begin{tabular}{|c|c|c|c|c|c|c|}
\hline \multirow{2}{*}{$\begin{array}{l}\text { Energy } \\
(\mathrm{MeV})\end{array}$} & \multirow{2}{*}{$\begin{array}{l}\text { Dosimeter } \\
\text { Type }\end{array}$} & \multicolumn{5}{|c|}{ PDD parameters } \\
\hline & & $\mathrm{D}_{\mathrm{s}}(\%)$ & $\begin{array}{l}\mathrm{R}_{100} \\
(\mathrm{~mm})\end{array}$ & $\mathrm{R}_{90}(\mathrm{~mm})$ & $\mathrm{R}_{50}(\mathrm{~mm})$ & $\mathrm{R}_{\mathrm{p}}(\mathrm{mm})$ \\
\hline \multirow[t]{5}{*}{6} & Advanced & 89.1 & 8.4 & 14.3 & 21.6 & 29.4 \\
\hline & Markus & & & & & \\
\hline & PinPoint & 85 & 8.1 & 13 & 19.6 & 26.7 \\
\hline & Semiflex & 86.9 & 9.8 & 14.5 & 21.3 & 28.4 \\
\hline & EBT-2 film & 86.6 & 9.5 & 14.8 & 21.6 & 28.6 \\
\hline \multirow[t]{4}{*}{8} & $\begin{array}{l}\text { Advanced } \\
\text { Markus }\end{array}$ & 89.9 & 12.1 & 21.6 & 31.6 & 41.7 \\
\hline & PinPoint & 89.5 & 12.2 & 21 & 30.9 & 40.8 \\
\hline & Semiflex & 88.2 & 14.1 & 22.7 & 32.6 & 42.7 \\
\hline & EBT-2 film & 90 & 14.8 & 22.5 & 32.2 & 42.1 \\
\hline \multirow[t]{4}{*}{10} & $\begin{array}{l}\text { Advanced } \\
\text { Markus }\end{array}$ & 91.6 & 15 & 27.3 & 40 & 52.3 \\
\hline & PinPoint & 91.7 & 15.7 & 26.5 & 39 & 51.3 \\
\hline & Semiflex & 89.8 & 17.8 & 28.9 & 41.3 & 53.3 \\
\hline & EBT-2 film & 92.2 & 16.3 & 27.2 & 39.8 & 52.2 \\
\hline \multirow[t]{4}{*}{12} & $\begin{array}{l}\text { Advanced } \\
\text { Markus }\end{array}$ & 93.1 & 16 & 31.6 & 46.7 & 61.3 \\
\hline & PinPoint & 93.1 & 16 & 31 & 46 & 60.2 \\
\hline & Semiflex & 91.7 & 19.8 & 34.2 & 48.8 & 62.7 \\
\hline & EBT-2 film & 91.5 & 18.1 & 33.1 & 47.2 & 61.5 \\
\hline
\end{tabular}

Table 4

The values of polarity correction factor at different energies of intraoperative electron beam, $\mathrm{K}_{\mathrm{Pol}}$, for ion chambers understudy.

\begin{tabular}{llllll}
\hline Chamber trade name & \multirow{2}{*}{ Operating voltage (V) } & \multicolumn{5}{l}{ Energy (MeV) } \\
\cline { 3 - 6 } & & 6 & 8 & 10 & 12 \\
\cline { 3 - 6 } & & 1.006 & 1.005 & 1.003 & 1.004 \\
Advanced Markus & 300 & 1.028 & 1.031 & 1.028 & 1.022 \\
Pinpoint & 400 & 1.018 & 1.015 & 1.024 & 1.030 \\
Semiflex & 400 & 1.010 & 1.005 & 1.003 & 1.001 \\
Roos & 200 & & & & \\
\hline
\end{tabular}

Roos and Semiflex chambers have higher $k_{s}$ values respect to the Advanced Markus and PinPoint chambers. This fact can be justified by the chamber electrode spacing and size of the sensitive volume. As described earlier, the Roos and Semiflex chambers have greater sensitive volume in comparison with the other studied chambers. With increasing the chamber electrode spacing and sensitive volume, both negative (or free electrons) and positive ions should traverse longer passes before collection which can increase the chance of recombination. Therefore, the rate of ion recombination would be higher for the chambers with larger sensitive volume and as a result, $\mathrm{k}_{\mathrm{s}}$ would be increased. Regarding this fact, applying a sufficiently high operating voltage to the chambers with large electrode spacing is mandatory. This high applied voltage decreases the charge collection time $(13 \mathrm{~ms}$ for Roos chamber at $200 \mathrm{~V}, 12 \mathrm{~ms}$ for Semiflex chamber at $400 \mathrm{~V}, 0.02 \mathrm{~ms}$ for Advanced Markus chamber at $300 \mathrm{~V}$ and $0.02 \mathrm{~ms}$ for PinPoint chamber at $400 \mathrm{~V} \mathrm{[19])} \mathrm{which} \mathrm{can} \mathrm{finally} \mathrm{improve} \mathrm{the} \mathrm{charge} \mathrm{collection}$ efficiency and reduce the $k_{s}$ factor. As reported by Scalchi et al. with increasing the Roos chamber voltage from 200 to $400 \mathrm{~V}$ the $\mathrm{k}_{\mathrm{s}}$ value decreases by about $19 \%$ at $45 \mathrm{mGy}$ dose per pulse value [8].

The comparison between obtained the $\mathrm{k}_{\mathrm{s}}$ values (derived by the third Boag model) for Roos and Advanced Markus chambers with those reported by Scalchi and Bruggmoser $[8,16]$ studies are listed in Table 6 . It should be mentioned that the reported dose per pulse values in our study have been calculated from the recorded pulse numbers by the LIAC treatment console after each irradiation. The pulse numbers corresponding to the administered MUs in each irradiation were employed to convert the absorbed dose (in terms of $\mathrm{cGy} / \mathrm{MU}$ ) to the dose per pulse value (in terms of mGy/Pulse). Furthermore, the Bruggmoser data in Table 6 were calculated according to the introduced Eq. (2) by the Bruggmoser study.

As presented by Table 6, there is a good agreement between the results of our study and reported $\mathrm{k}_{\mathrm{s}}$ values by Scalchi et al., so that the maximum difference between the obtained results was equal to $0.3 \%$ which can be due to the slightly different DPP values and chamber voltage (in the case of Advanced Markus).

On the other hand, the maximum difference between our results with those reported by Bruggmoser et al. was about 6.3\%. This considerable difference is mainly attributed to the zero linear extrapolation method (Jaffe plots) employed by the mentioned study. As explained by Laitano et al. using the Jaffe plots for $\mathrm{k}_{\mathrm{s}}$ determination in high-dose perpulse electron beam can introduce the deviations up to $6 \%$ relative to the calculated values based on Laitano formalism which is in accordance with the observed difference $(6.3 \%)$ in our study.

The measured intraoperative electron dose (in terms of cGy/MU) by different ion chambers at the reference condition, based on Eq. (2), are reported in Table 7 for $12 \mathrm{MeV}$ electron energy.

According to Table 7, the maximum difference between the measured doses by different ion chambers was equal to $1.1 \%$ (respect to the Advanced Markus dosimetry) which can be considered as an acceptable result. The repeatability of chamber response (in terms of collected charge per $\mathrm{MU}$ ) in three successive irradiations was equal to $0.23 \%$, $0.11 \%, 0.19 \%$, and $0.38 \%$ for Advanced Markus, Roos, Semiflex and 
Table 5

Calculated quality conversion factor at both $\mathrm{Z}_{\mathrm{ref}}$ and $\mathrm{Z}_{\max }$ for considered ion chambers at different electron energies.

\begin{tabular}{|c|c|c|c|c|c|c|c|c|c|c|c|c|c|}
\hline \multirow[t]{2}{*}{$\begin{array}{l}\text { Chamber trade } \\
\text { name }\end{array}$} & \multirow[t]{2}{*}{$\begin{array}{l}\text { Operating } \\
\text { voltage }(\mathrm{V})\end{array}$} & \multicolumn{2}{|c|}{$\begin{array}{l}\text { Energy }(\mathrm{MeV}) \\
6\end{array}$} & \multirow{2}{*}{$\begin{array}{l}\text { Relative } \\
\text { difference } \\
-(\%)\end{array}$} & \multicolumn{2}{|c|}{$\begin{array}{l}\text { Energy }(\mathrm{MeV}) \\
8\end{array}$} & \multirow{2}{*}{$\begin{array}{l}\text { Relative } \\
\text { difference } \\
-(\%)\end{array}$} & \multicolumn{2}{|c|}{$\begin{array}{l}\text { Energy }(\mathrm{MeV}) \\
10\end{array}$} & \multirow{2}{*}{$\begin{array}{l}\text { Relative } \\
\text { difference } \\
-(\%)\end{array}$} & \multicolumn{2}{|c|}{$\begin{array}{l}\text { Energy }(\mathrm{MeV}) \\
12\end{array}$} & \multirow[t]{2}{*}{$\begin{array}{l}\text { Relative } \\
\text { difference (\%) }\end{array}$} \\
\hline & & $\begin{array}{l}\mathrm{K}_{\mathrm{Q}, \mathrm{Q} 0} \\
\left(\mathrm{Z}_{\max }\right)\end{array}$ & $\begin{array}{l}\mathrm{K}_{\mathrm{Q}, \mathrm{Q0}} \\
\left(\mathrm{Z}_{\mathrm{ref}}\right)\end{array}$ & & $\begin{array}{l}\mathrm{K}_{\mathrm{Q}, \mathrm{Q} 0} \\
\left(\mathrm{Z}_{\max }\right)\end{array}$ & $\begin{array}{l}\mathrm{K}_{\mathrm{Q}, \mathrm{Q0}} \\
\left(\mathrm{Z}_{\mathrm{ref}}\right)\end{array}$ & & $\begin{array}{l}\mathrm{K}_{\mathrm{Q}, \mathrm{Q} 0} \\
\left(\mathrm{Z}_{\max }\right)\end{array}$ & $\begin{array}{l}\mathrm{K}_{\mathrm{Q}, \mathrm{Q} 0} \\
\left(\mathrm{Z}_{\mathrm{ref}}\right)\end{array}$ & & $\begin{array}{l}\mathrm{K}_{\mathrm{Q}, \mathrm{Q} 0} \\
\left(\mathrm{Z}_{\max }\right)\end{array}$ & $\begin{array}{l}\mathrm{K}_{\mathrm{Q}, \mathrm{Q0}} \\
\left(\mathrm{Z}_{\mathrm{ref}}\right)\end{array}$ & \\
\hline $\begin{array}{l}\text { Advanced } \\
\text { Markus }\end{array}$ & 300 & 0.931 & 0.944 & 1.4 & 0.914 & 0.930 & 1.7 & 0.906 & 0.921 & 1.6 & 0.894 & 0.915 & 2.3 \\
\hline PinPoint & 400 & - & - & - & - & - & - & - & - & - & 0.905 & 0.924 & 2.1 \\
\hline Semiflex & 400 & - & - & - & - & - & - & - & - & - & 0.893 & 0.909 & 1.8 \\
\hline Roos & 200 & 0.929 & 0.942 & 1.4 & 0.914 & 0.929 & 1.6 & 0.902 & 0.920 & 2.0 & 0.895 & 0.915 & 2.2 \\
\hline
\end{tabular}

PinPoint chamber, respectively. This finding indicates a reproducible performance in intraoperative electron beam dosimetry for all studied ion chambers.

\section{Conclusion}

The performance of different parallel plate and cylindrical ion chamber dosimeters for relative and absolute dosimetry in reference condition of high dose per pulse electron beam was evaluated in this study.

The results of relative dosimetry in PDD measurement showed that all of the studied ion chambers have a desirable performance when are compared with the Gafchromic EBT2 film dosimetry results. Treatment planning in IOERT is based on PDD only, hence the PDD is a very important parameter. Looking at the full PDDs, the Advanced Markus chamber is the best-suited chamber for PDD measurement. Only the buildup region would be better reflected by the cylindrical chambers.

The $\mathrm{k}_{\mathrm{Q}_{\mathrm{Q}} \mathrm{Q}_{0}}$ and $\mathrm{k}_{\mathrm{s}}$ of intraoperative electron beam were different from those obtained according to the routine formalisms of TRS-398 protocol. These differences were mainly due to the different measurement depth $\left(Z_{\max }\right.$ instead of $Z_{\text {ref }}$ ) and high dose per pulse nature of employed electron beam. The calculated values for $\mathrm{k}_{\mathrm{s}}$ and $\mathrm{k}_{\mathrm{Q}_{\mathrm{Q}}}$ were lower than expected ones by TRS-398 protocol. Therefore, ignoring the recommended specific procedures in the determination of chamber correction factors causes the overestimation of measured dose which can finally lead to the wrong MU calculation and inaccurate administered dose to the patient.

Although the adjoining formalism by TRS-398 protocol (as described in Appendix II of TRS-398 protocol) was used to determine the $\mathrm{k}_{\mathrm{Q}_{Q_{0}}}$, further attention should be paid in this regard. This concern is
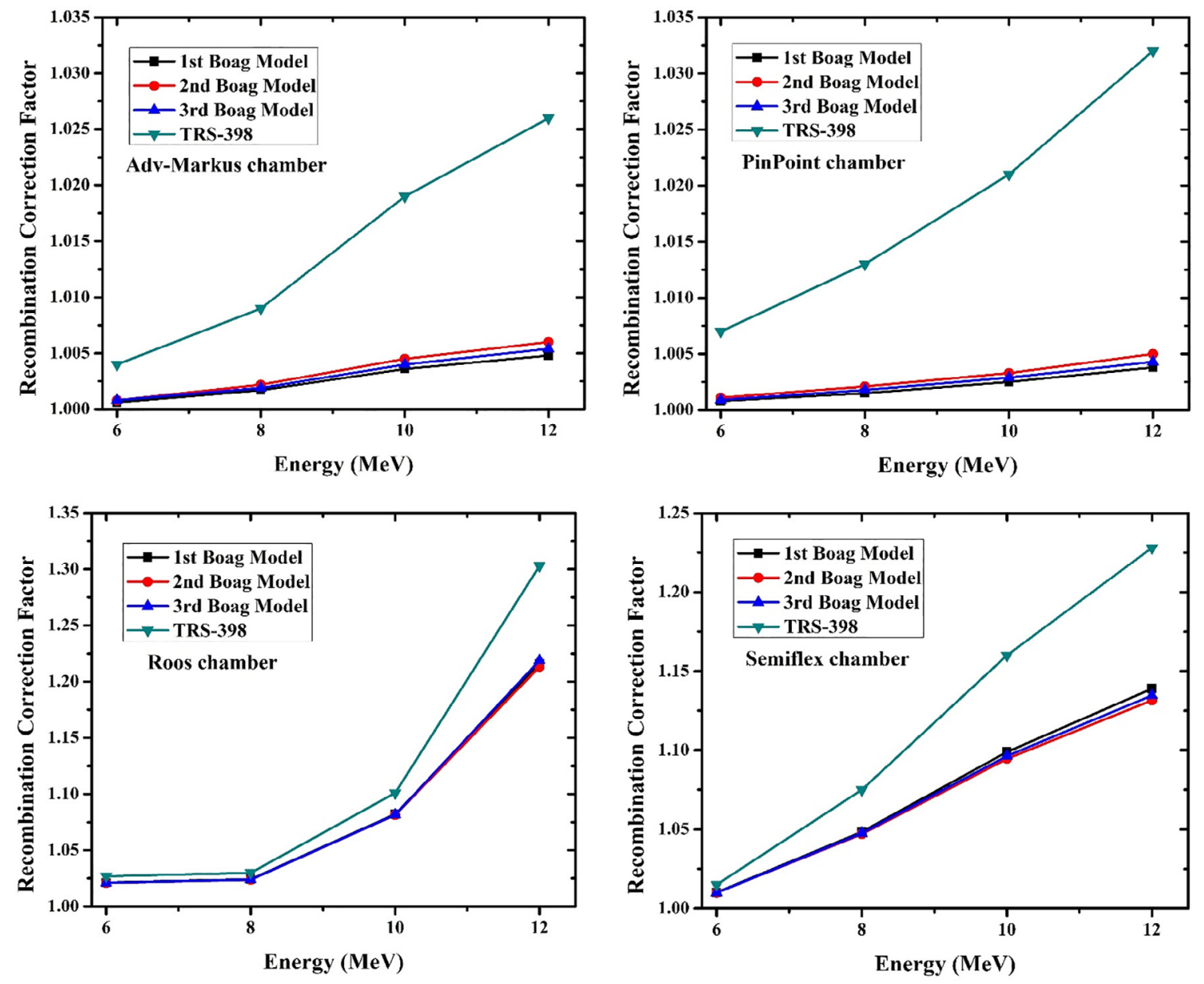

Fig. 6. Calculated recombination correction factors for ion chambers understudy at different electron energies according to various Boag models. The corresponding simple TVA based results are also presented for comparison. 
Table 6

Comparison between obtained $k_{s}$ values in current study and those reported by other literatures $[8,16]$.

\begin{tabular}{|c|c|c|c|c|}
\hline Study & Chamber trade name & Operating voltage (V) & Dose per pulse (DPP) (mGy/pulse) & $\mathrm{k}_{\mathrm{s}}$ \\
\hline \multirow{2}{*}{ Bruggmoser et al. } & Roos & 200 & 5 & 1.043 \\
\hline & Roos & 200 & 35 & 1.296 \\
\hline \multirow[t]{4}{*}{ Scalchi et al. } & Roos & 200 & 4 & 1.025 \\
\hline & Roos & 200 & 33 & 1.215 \\
\hline & Advanced Markus & 400 & 4 & 1 \\
\hline & Advanced Markus & 400 & 33 & 1.005 \\
\hline \multirow[t]{4}{*}{ Current work } & Roos & 200 & 5 & 1.021 \\
\hline & Roos & 200 & 35 & 1.219 \\
\hline & Advanced Markus & 300 & 5 & 1.001 \\
\hline & Advanced Markus & 300 & 35 & 1.005 \\
\hline
\end{tabular}

Table 7

The measured dose by employed ion chambers at $12 \mathrm{MeV}$ electron energy.

\begin{tabular}{lll}
\hline Chamber trade name & $\begin{array}{l}\text { Operating voltage } \\
\text { (V) }\end{array}$ & $\begin{array}{l}\text { Energy (MeV) } \\
12 \\
\text { Measured dose (cGy/MU) at the } \\
\text { depth of maximum dose }\end{array}$ \\
& & 1.000 \\
Advanced Markus & 300 & 0.989 \\
Pinpoint & 400 & 1.007 \\
Semiflex & 400 & 1.011 \\
Roos & 200 & \\
\hline
\end{tabular}

due to the different energy characteristics of intraoperative electron compared to the conventional electron ones which can have a substantial effect on chamber perturbation correction factors $\left(\mathrm{P}_{\text {wall }}\right.$ and $\mathrm{P}_{\text {cav }}$ ) that should be considered in $\mathrm{k}_{\mathrm{Q}, \mathrm{Q}_{0}}$ calculation (these factors are assumed to be unitary in TRS-398 protocol for studied ion chambers). Therefore, providing a dedicated dosimetry protocol for high dose per pulse intraoperative electron beam dosimetry is a mandatory issue which should consider all of the deviations from routine electron dosimetry formalisms and include the updated correction factors for employed ion chambers in intraoperative electron dosimetry.

The response repeatability (in terms of $\mathrm{nC} / \mathrm{MU}$ ) of studied chambers was less than $0.4 \%$. In addition, the difference between the measured doses by various chambers was about $1 \%$. Measured dose by Advanced Markus ion chamber had the best accordance with the pre-set dose ( $1 \mathrm{cGy} / \mathrm{MU}$ ) by the manufacture (Sordina, SpA).

\section{Declaration of interest}

The authors declare that there are neither conflicts of interest associated with this manuscript nor significant financial support that could have influenced its outcomes.

\section{References}

[1] Gunderson LL, Willett CG, Calvo FA, Harrison LB. Intraoperative irradiation: techniques and results. Humana Press; 2011.

[2] Calvo FA, Aristu JJ, Abuchaibe O, Rebollo J, Fernandez Hidalgo O, Zudaire J, et al. Intraoperative and external preoperative radiotherapy in invasive bladder cancer: effect of neoadjuvant chemotherapy in tumor downstaging. Am J Clin Oncol 1993;16(1):61-6.

[3] Valentini V, Morganti AG, De Franco A, Coco C, Ratto C, Battista Doglietto G, et al. Chemoradiation with or without intraoperative radiation therapy in patients with locally recurrent rectal carcinoma: prognostic factors and long term outcome. Cancer 1999;86(12):2612-24.

[4] Krempien R, Roeder F, Oertel S, Weitz J, Hensley FW, Timke C, et al. Intraoperative electron-beam therapy for primary and recurrent retroperitoneal soft-tissue sarcoma. Int J Radiat Oncol Biol Phys 2006;65(3):773-9.

[5] Valentini V, Calvo F, Reni M, Krempien R, Sedlmayer F, Buchler MW, et al. Intraoperative radiotherapy (IORT) in pancreatic cancer: joint analysis of the ISIORTEurope experience. Radiother Oncol 2009;91(1):54-9.

[6] Veronesi U, Orecchia R, Luini A, Galimberti V, Gatti G, Intra M, et al. Full-dose intraoperative radiotherapy with electrons during breast-conserving surgery: experience with 590 cases. Ann Surg 2005;242(1):101-6.
[7] Beddar AS, Biggs PJ, Chang S, Ezzell GA, Faddegon BA, Hensley FW, et al. Intraoperative radiation therapy using mobile electron linear accelerators: report of AAPM Radiation Therapy Committee Task Group No. 72. Med Phys 2006;33(5):1476-89.

[8] Scalchi P, Ciccotelli A, Felici G, Petrucci A, Massafra R, Piazzi V, et al. Use of parallel-plate ionization chambers in reference dosimetry of NOVAC and LIAC((R)) mobile electron linear accelerators for intraoperative radiotherapy: a multi-center survey. Med Phys 2017;44(1):321-32.

[9] Andreo P, Burns DT, Hohlfeld K, Huq MS, Kanai T, Laitano F, et al. Absorbed dose determination in external beam radiotherapy: an international code of practice for dosimetry based on standards of absorbed dose to water. IAEA TRS-398, 2006.

[10] Almond PR, Biggs PJ, Coursey BM, Hanson WF, Huq MS, Nath R, et al. AAPM's TG 51 protocol for clinical reference dosimetry of high-energy photon and electron beams. Med Phys 1999;26(9):1847-70.

[11] Laitano RF, Guerra AS, Pimpinella M, Caporali C, Petrucci A. Charge collection efficiency in ionization chambers exposed to electron beams with high dose per pulse. Phys Med Biol 2006;51(24):6419-36.

[12] Baghani HR, Aghamiri SM, Mahdavi SR, Akbari ME, Mirzaei HR. Comparing the dosimetric characteristics of the electron beam from dedicated intraoperative and conventional radiotherapy accelerators. J Appl Clin Med Phys 2015;16(2):5017.

[13] Heidarloo N, Baghani HR, Aghamiri SM, Mahdavi SR, Akbari ME. Commissioning of beam shaper applicator for conformal intraoperative electron radiotherapy. Appl Radiat Isot 2017;123:69-81.

[14] Robatjazi M, Mahdavi S, Baghani H, Mirzaei H, Mousavi M, Nafissi N, et al. Monte Carlo simulation of electron beams produced by LIAC intraoperative radiation therapy accelerator. J Biomed Phys Eng 2018;8(1):43.

[15] Baghani HR, Aghamiri SMR, Mahdavi SR, Robatjazi M, Zadeh AR, Akbari ME, et al Dosimetric evaluation of Gafchromic EBT2 film for breast intraoperative electron radiotherapy verification. Phys Med 2015;31(1):37-42.

[16] Bruggmoser G, Saum R, Schmachtenberg A, Schmid F, Schüle E. Determination of the recombination correction factor $\mathrm{kS}$ for some specific plane-parallel and cylindrical ionization chambers in pulsed photon and electron beams. Phys Med Biol 2006;52(2):N35.

[17] Besheli MG, Simiantonakis I, Zink K, Budach W. Determination of the ion recombination correction factor for intraoperative electron beams. Zeitschrift fuer Medizinische Physik 2016;26(1):35-44.

[18] Baghani HR, Aghamiri SMR, Mahdavi SR, Akbari ME, Mirzaei HR. Comparing the dosimetric characteristics of the electron beam from dedicated intraoperative and conventional radiotherapy accelerators. J Appl Clin Med Phys 2015;16(2):62-72.

[19] PTW. Ionizing radiation detectors. 20178 July 2018]; Available from: www.emfjapan.com/ptw/img/PDF/PTW_all_detectors.pdf.

[20] Almond P. The dosimetry of pulsed radiation, ICRU Report No. 34. Med Phys 1984;11(2):222.

[21] Righi S, Karaj E, Felici G, Di Martino F. Dosimetric characteristics of electron beams produced by two mobile accelerators, Novac7 and Liac, for intraoperative radiation therapy through Monte Carlo simulation. J Appl Clin Med Phys 2013;14(1):3678.

[22] Di Venanzio C, Marinelli M, Tonnetti A, Verona-Rinati G, Falco MD, Pimpinella M, et al. Characterization of a microDiamond detector in high-dose-per-pulse electron beams for intra operative radiation therapy. Phys Med 2015;31(8):897-902.

[23] Das IJ, Cheng CW, Watts RJ, Ahnesjo A, Gibbons J, Li XA, et al. Accelerator beam data commissioning equipment and procedures: report of the TG-106 of the Therapy Physics Committee of the AAPM. Med Phys 2008;35(9):4186-215.

[24] Robatjazi M, Mahdavi SR, Takavr A, Baghani HR. Application of Gafchromic EBT2 film for intraoperative radiation therapy quality assurance. Phys Med 2015;31(3):314-9.

[25] Low DA, Harms WB, Mutic S, Purdy JA. A technique for the quantitative evaluation of dose distributions. Med Phys 1998;25(5):656-61.

[26] Di Martino F, Giannelli M, Traino AC, Lazzeri M. Ion recombination correction for very high dose-per-pulse high-energy electron beams. Med Phys 2005;32(7):2204-10.

[27] Boag JW, Hochhauser E, Balk OA. The effect of free-electron collection on the recombination correction to ionization measurements of pulsed radiation. Phys Med Biol 1996;41(5):885-97.

[28] Knoll GF. Radiation detection and measurement. 4th ed. John Wiley \& Sons Inc.; 2010. 